\title{
Comment
}

\section{Freedom: Facts and Figments}

\section{PETER TAYLOR GOOBY*}

'Freedom is more than a word, more than the base coinage of statesmen... She is mortal. . .and made in the image of simple men'

C. Day Lewis

Vol. 11, part 2 of the Journal of Social Policy was devoted to the theme of 'Freedom and the Welfare State'. The purpose of this note is to suggest that the approach adopted in some of the essays is unnecessarily restrictive, that the constraints derive from implicit assumptions of method and that they deflect attention from alternative approaches to the problem of assessing the freedom of social arrangements.

In an incisive introductory essay, Albert Weale outlines the task of evaluating the relationship between freedom and the welfare state:

we. . .need an account of the idea of freedom and an understanding of the way in which welfare state institutions typically function...The political theorist will plot the varying conceptions of freedom that may be held, and the social administrator will investigate whether there are...social institutions which exemplify and enable us to understand what freedom in practice means (p. 145).

In this sphere, as in others, the enhanced productivity resulting from a division of labour may not be an unambiguous gain. Two interlinked problems emerge. First, setting analytic and empiric work in separate compartments is likely to favour the production of a criterion of freedom that claims independence from dominant currents of thought about freedom in any particular society. People have understood - and struggled for - rather different things in the name of freedom at different times and in different places; a comparison of the kind of economic basis for freedom the emergent bourgeoisie advanced at the dawn of the modern era with Joan Higgins' argument that freedom in the contemporary world is dependent on economic security (p. 198) illustrates the point. Similarly, David Green shows that freedom has been analysed in at least two contradictory ways in

* Lecturer in Social Policy, University of Kent. 


\section{Peter Taylor Gooby}

the tradition of political thought - as the outcome of the extension of state power against other institutions, and as the outcome of limitation of that power (p. 240).

The fact that a society - independent criterion of freedom minimizes the importance of what people think leads to the second point. If an abstracted conception of freedom is to be deployed as a yardstick in social affairs, how is it to be justified? It is interesting to note that at a number of points some essays use psychological evidence to support assertions about the extent to which people think welfare institutions might enhance freedom. But opinions can differ. Unless a theory of why particular opinions are to be privileged as a criterion is provided, problems of relativism arise. For example, some varieties of Marxism evade the difficulty by claiming that values are relative to social environment, but that institutions develop in a coherent and vaguely progressive way which gives primacy to the culminating values of communism.

The classic distinction between positive and negative conceptions of freedom demands choice at a theoretical level, but provides no clear basis for it. Robert Goodin's approach to this problem illustrates the difficulty of constructing adequate society - independent criteria of freedom. He conflates positive and negative approaches, using McCallum's analysis which 'unpacks' discourse on freedom to reveal implicit references to both negative and positive aspects - obstacles and objectives to actions (p. 152). The formula of freedom from constraint to do something is applied to nine major arguments about the welfare state. Various strategies for 'grounding' the notion of freedom are employed. Two are of most interest to us. These approach the view that social circumstances influence ideas most closely. One is the claim that the imposition of uniform services by the state frees people 'from temptations, which may have been psychologically irresistible, to behave in an immorally self-serving fashion' (p. 160). Self-interest is less desirable than compulsory principled action either because people (in their calmer moments, when not, for example, in the grip of compulsion to buy privileged education for their children) prefer the principle, or because moral principle is analytically better. A similar argument is advanced about the moralizing effect of coercion into welfare institutions, although here the psychological status of the argument is clearer (p. 171). People feel 'moral indignation' at situations where the existence of institutions such as black markets leads them to violate moral values out of self-interest.

The arguments rest on assumed priority either of moral principles over the principle of self-interest or of one set of preferences for social organization (which people sometimes voice) over another set (which they sometimes follow). In either case, it is not clear why freedom in one area is superior to 
freedom in the other. The first argument depends on a society - independent deduction of principles of morality which simply takes the problem of the legitimation of the Archimedean point back one stage. The second approach is vulnerable to shifts in public opinion. The problems in deducing opinions from statement rather than action are well known.

Joan Higgins' essay avoids the problem of relativism in a different way. A range of conceptions of freedom, including freedom of choice, of disposition and of action are identified (pp. 186-92). The problem of establishing general criteria for ordering observations of the impact of welfare in these various areas is not salient. The argument focuses on particular discussion of 'who has gained', 'who has lost', and 'why'? (p. 194). No general principle appropriate to the organization of an overall criterion emerges, although the paper suggests that many freedoms are secondary, 'contingent upon the primary condition of freedom from economic need' (p. 177). Since the approach implicitly separates 'welfare state' from 'economy' the relation remains unanalysed.

Unless more adequate normative foundations for freedom are constructed, the programme of separating analytic from empirical work faces difficulties. The role of information on what people actually think about the concepts to be analysed becomes secondary, and the problem of evaluating the contribution of popular ideas through a theory of ideology is given little attention. It may be that empirical data has a more forceful role in resolving problems of relativism than that of the under-labourer, digging out evidence for the abstract construction of the political theorist. 